\title{
In Situ $\mathrm{CO}_{2}$ Efflux from Leaf Litter Layer Showed Large Temporal Variation Induced by Rapid Wetting and Drying Cycle
}

\author{
Mioko Ataka ${ }^{1 *}$, Yuji Kominami ${ }^{2}$, Kenichi Yoshimura ${ }^{2}$, Takafumi Miyama ${ }^{2}$, Mayuko Jomura ${ }^{3}$, \\ Makoto Tani ${ }^{1}$
}

1 Laboratory of Forest Hydrology, Division of Environmental Science and Technology, Graduate School of Agriculture, Kyoto University, Kyoto, Japan, 2 Kansai Research Center, Forestry and Forest Products Research Institute (FFPRI), Kyoto, Japan, 3 College of Bioresource Sciences, Nihon University, Fujisawa, Kanagawa, Japan

\begin{abstract}
We performed continuous and manual in situ measurements of $\mathrm{CO}_{2}$ efflux from the leaf litter layer $\left(R_{\mathrm{LL}}\right)$ and water content of the leaf litter layer (LWC) in conjunction with measurements of soil respiration $\left(R_{\mathrm{S}}\right)$ and soil water content (SWC) in a temperate forest; our objectives were to evaluate the response of $R_{\mathrm{LL}}$ to rainfall events and to assess temporal variation in its contribution to $R_{\mathrm{S}}$. We measured $R_{\mathrm{LL}}$ in a treatment area from which all potential sources of $\mathrm{CO}_{2}$ except for the leaf litter layer were removed. Capacitance sensors were used to measure LWC. $R_{\mathrm{LL}}$ increased immediately after wetting of the leaf litter layer; peak $R_{\mathrm{LL}}$ values were observed during or one day after rainfall events and were up to 8.6-fold larger than $R_{\mathrm{LL}}$ prior to rainfall. $R_{\mathrm{LL}}$ declined to pre-wetting levels within 2-4 day after rainfall events and corresponded to decreasing LWC, indicating that annual $R_{\mathrm{LL}}$ is strongly influenced by precipitation. Temporal variation in the observed contribution of $R_{\mathrm{LL}}$ to $R_{\mathrm{S}}$ varied from nearly zero to $51 \%$. Continuous in situ measurements of $\mathrm{LWC}$ and $\mathrm{CO}_{2}$ efflux from leaf litter only, combined with measurements of $R_{\mathrm{S}}$, can provide robust data to clarify the response of $R_{\mathrm{LL}}$ to rainfall events and its contribution to total $R_{\mathrm{S}}$.
\end{abstract}

Citation: Ataka M, Kominami Y, Yoshimura K, Miyama T, Jomura M, et al. (2014) In Situ $\mathrm{CO}_{2}$ Efflux from Leaf Litter Layer Showed Large Temporal Variation Induced by Rapid Wetting and Drying Cycle. PLoS ONE 9(10): e108404. doi:10.1371/journal.pone.0108404

Editor: Ben Bond-Lamberty, DOE Pacific Northwest National Laboratory, United States of America

Received April 30, 2014; Accepted August 26, 2014; Published October 1, 2014

Copyright: (c) 2014 Ataka et al. This is an open-access article distributed under the terms of the Creative Commons Attribution License, which permits unrestricted use, distribution, and reproduction in any medium, provided the original author and source are credited.

Data Availability: The authors confirm that all data underlying the findings are fully available without restriction. All relevant data are within the paper.

Funding: Funding was provided by the Japan Society for the Promotion of Science (JSPS; grant number 25-2482 (http://www.jsps.go.jp/english/index.html)) Grant-in-Aid for Scientific Research (B) (20380182 (http://www.jsps.go.jp/english/index.html)). The funders had no role in study design, data collection and analysis, decision to publish, or preparation of the manuscript.

Competing Interests: The authors have declared that no competing interests exist.

* Email: teshimamioko@yahoo.co.jp

\section{Introduction}

Efflux of $\mathrm{CO}_{2}$ from the soil surface (soil respiration; $R_{\mathrm{S}}$ ), which is the sum of respiration by autotrophs and heterotrophs, is an important component of total $\mathrm{CO}_{2}$ efflux from forest ecosystems [1-3]. The $R_{\mathrm{S}}$ : total ecosystem respirations varied from $58 \%$ to $76 \%$ in a mixed coniferous-deciduous forest [4], depending on interannual and seasonal changes in autotrophic and heterotrophic respiration; variability in $R_{\mathrm{S}}$ can affect the forest carbon balance on daily and seasonal time scales. To explain the cause of variability in $R_{\mathrm{S}}$, many studies have attempted to separate differing sources of $\mathrm{Rs}$ and to examine factors controlling $\mathrm{CO}_{2}$ efflux rate from each source [5-7]. Especially in forest ecosystems, heterotrophic respiration consists of $\mathrm{CO}_{2}$ efflux from various sources (e.g., leaf and root litter, woody debris, soil organic matter) and their rates are controlled by their specific environmental condition such as water content (WC) and temperature [8], physical properties of the substrate (e.g., density and structure) $[9,10]$, and chemical properties (e.g., labile and recalcitrant carbon) $[11,12]$. Moreover, $\mathrm{CO}_{2}$ efflux from the various heterotrophic sources responds differently to these controlling factors, which illustrates the complexity of $R_{\mathrm{S}}$. In recent decades, a variety of methods for separating components of heterotrophic respiration and for determining their contribution to total $R_{\mathrm{S}}$ have been developed $[9,13]$.

Among heterotrophic sources of $\mathrm{CO}_{2}$, the leaf litter layer (Llayer) is a significant reservoir of degradable carbon and a large potential source of $\mathrm{CO}_{2}$ efflux from forest soils [14]. In temperate forests, the contribution of $\mathrm{CO}_{2}$ efflux from the L-layer (leaf litter respiration; $R_{\mathrm{LL}}$ ) to $R_{\mathrm{S}}$ is reported to range from $23 \%$ to $48 \%$ $[13,15,16]$. The L-layer is in direct contact with rainfall, solar radiation, and wind, and environmental conditions (e.g., WC and temperature) can change more dynamically in the L-layer than in lower soil layers. Rapid and transient temporal variation in $\mathrm{WC}$ of the L-layer has been observed, especially in warm climates $[16,17]$. Heterotrophic respiration responds rapidly to changes in moisture status $[17,18]$; therefore, rapid and transient wetting and drying cycles would produce large temporal variations in $R_{\mathrm{LL}}$. This would significantly affect variation in $R_{\mathrm{S}}[17,19]$, suggesting that $R_{\mathrm{LL}}$ is an important controller of temporal (daily and seasonal) patterns in the carbon balance in warm regions $[19,20]$.

Several methods for measuring $R_{\mathrm{LL}}$ and for calculating its contribution to $R_{\mathrm{S}}$ have been explored. Cisneros-Dozal et al. [21] used an isotope mass balance method and reported that the contribution of $R_{\mathrm{LL}}$ to $R_{\mathrm{S}}$ increased from $5 \%$ to $37 \%$ in response to water addition after transient drought. Deforest et al. [15] 
determined that the annual contribution of $R_{\mathrm{LL}}$ to $R_{\mathrm{S}}$ was $48 \%$ $\pm 12 \%$ by measuring $R_{\mathrm{S}}$ with and without the L-layer, and the ratio was consistent over a range of environmental conditions. However, there is little information about temporal variation in $R_{\mathrm{LL}}$ in relation to rainfall events because of the difficulty of continuous and direct measurement of $R_{\mathrm{LL}}$ in situ.

To continuously measure $\mathrm{CO}_{2}$ efflux from the L-layer only, in parallel with measurement of $R_{\mathrm{S}}$, we developed an approach for measuring $R_{\mathrm{LL}}$ using an automated chamber method in a treatment area from which all $\mathrm{CO}_{2}$ sources except for the Llayer were removed. In parallel with $R_{\mathrm{LL}}$ and $R_{\mathrm{S}}$ measurements, we continuously measured water content of the L-layer (LWG) and soil water content (SWC). LWC was measured using a method developed by Ataka et al. [22], in which intact leaf litter was attached to surrounding capacitance sensors. Sensors were also placed on top of the L-layer and at the boundary between the Land mineral layers. From these continuous in situ measurements, we investigated the response of $R_{\mathrm{LL}}$ to rainfall events by comparing $R_{\mathrm{LL}}$ with $R_{\mathrm{S}}$, and examined temporal variation in the contribution of $R_{\mathrm{LL}}$ to $R_{\mathrm{S}}$ in a warm temperate forest in Japan.

\section{Materials and Methods}

\section{Ethics statement}

The study site (Yamashiro Experimental Forest) is maintained by the Forestry and Forest Products Research Institute. All necessary permits were obtained for the field study, and the study did not involve endangered or protected species.

\section{Study site}

Our observations of $R_{\mathrm{LL}}$ and $R_{\mathrm{S}}$ were conducted at the Yamashiro Experimental Forest in southern Kyoto Prefecture, Japan $\left(34^{\circ} 47^{\prime} \mathrm{N}, 135^{\circ} 50^{\prime} \mathrm{E}\right)$. The study site is a 1.7 -ha watershed characterized by an annual mean air temperature of $15.5^{\circ} \mathrm{C}$ (maximum, $34.8^{\circ} \mathrm{C}$; minimum, $-3.9^{\circ} \mathrm{C}$ ) and annual precipitation of $1449 \mathrm{~mm}$ [2]. The rainy season generally occurs from early June to mid-July. Daily rates of evaporation from the forest floor are $0.4-0.8 \mathrm{~mm} \mathrm{day}^{-1}$ for $1-2$ days after precipitation, declining thereafter to $0.2-0.3 \mathrm{~mm} \mathrm{day}^{-1}$ [23]. The soils are Regosols with sandy loam or loamy sand texture and contain fine gravel (53\% by mass) composed of residual quartz crystals from granite parent material [24]. These are immature soils in which the thickness of the A horizon is $2-3 \mathrm{~cm}$. Deciduous broad-leaved, evergreen broad-leaved, and coniferous tree species account for $66 \%, 28 \%$, and $6 \%$ of the living tree biomass, respectively [25]. The forest is dominated by Quercus serrata Thunb., which accounts for approximately $33 \%$ of the biomass. The L-layer (approximately 3-4 cm thick) consists mainly of fresh Q. serrata litter. There is no substantial organic horizon below the L-layer.

\section{Automated chamber method for measuring leaf litter respiration and soil respiration}

We measured $R_{\mathrm{LL}}$ and $R_{\mathrm{S}}$ using an automated dynamic chamber system with an infrared gas analyzer (IRGA, GMP343; Vaisala Group, Vantaa, Finland) (Fig. 1A). The system consisted of two automated circular chambers for $R_{\mathrm{LL}}$ and $R_{\mathrm{S}}$ measurement, four solenoid valves, a pump, mass flow meter, and IRGA. The chambers (surface area $320 \mathrm{~cm}^{2}$ ) were made from PVC collars with clear acrylic lids that can be opened and closed automatically using an air cylinder. Air was supplied to the cylinder from a compressor. To ensure a seal between the chamber and the closed lid, a soft rubber gasket was attached to the top edge of the chamber. Opening and closing of the chamber lid and solenoid valves of each chamber were regulated synchronously by a control unit (ZEN, OMRON, Kyoto, Japan).

The duration of measurement of $\mathrm{CO}_{2}$ concentration inside each chamber was 6 min and was performed twice per hour. The $\mathrm{CO}_{2}$ concentration in each chamber was recorded at 1 -s intervals using a data logger (GL220, Graphtec, Kanagawa, Japan). We calculated $R_{\mathrm{LL}}$ and $R_{\mathrm{S}}$ from the increase in $\mathrm{CO}_{2}$ concentration $\left(\Delta \mathrm{C}_{\mathrm{CO} 2}\right)$ using linear regression. Data from the first 2 min were discarded to avoid effects of closing the chamber. $R_{\mathrm{LL}}$ and $R_{\mathrm{S}}$ were calculated using the following equation:

$$
R=\frac{\Delta C_{\mathrm{CO}_{2}}}{10^{6}} \times \frac{V}{V_{\text {air }}} \frac{273.2}{273.2+T} \times M_{\mathrm{CO}_{2}} \times \frac{1}{A},
$$

where $R$ is respiration $\left(\mathrm{mg} \mathrm{CO}_{2} \mathrm{~m}^{-2} \mathrm{~s}^{-1}\right), \Delta \mathrm{C}_{\mathrm{CO} 2}$ is the change in $\mathrm{CO}_{2}$ concentration per unit time $\left(\mathrm{CO}_{2} \mathrm{ppm} \mathrm{s}^{-1}\right), V$ is the volume of the system $(\mathrm{L}), V_{\text {air }}$ is the standard gas volume $\left(22.41 \mathrm{~L} \mathrm{~mol}^{-1}\right)$, $T$ is temperature inside the chamber $\left({ }^{\circ} \mathrm{C}\right), M_{\mathrm{CO} 2}$ is the molecular weight of $\mathrm{CO}_{2}\left(44.01 \mathrm{~g} \mathrm{~mol}^{-1}\right)$, and $A$ is the soil surface area covered by the chamber $\left(\mathrm{m}^{2}\right)$.

To continuously measure $\mathrm{CO}_{2}$ efflux from the L-layer only, we developed an approach for measuring $R_{\mathrm{LL}}$ by using an automated chamber method in a treatment area in which all potential $\mathrm{CO}_{2}$ sources (e.g., organic soil and fine roots) except for the L-layer were replaced with combusted granite soil (Fig. 1B). To prepare the treatment area $\left(1 \mathrm{~m}^{2}\right)$, we removed surface soil (approximately $5 \mathrm{~cm}$ ). An acrylic board was placed on the bottom and sides of the treatment area to prevent penetration of roots; a drain tube was located at the bottom of the board to prevent the treatment area from flooding with rainwater. The treatment area was then filled with granite soil combusted in a muffle furnace $\left(500^{\circ} \mathrm{C}\right.$ for 1 day). For $R_{\mathrm{LL}}$ measurement, we placed a PVC collar $\left(320-\mathrm{cm}^{2}\right.$ surface area) and acrylic board below the collar. The board was set at a slight incline to drain rainwater from the collar. We added $15 \mathrm{~g}$ of newly fallen leaf litter, which represents the average litterfall mass per unit ground surface area at this site, to the collar. We added the leaf litter to each chamber on January 2012. To acquire data on the temporal variation in $R_{\mathrm{LL}}$ of fresh leaf litter, we replaced the litter with newly fallen leaf litter in January 2013. The collar for measurement of $R_{\mathrm{S}}$ was placed near the treatment area for $R_{\mathrm{LL}}$ measurement and the L-layer inside the collar was removed and leaf litter was supplied similarly as for measurement of $R_{\mathrm{LL}}$. To prevent incorporation of newly fallen litter, we placed a mesh sheet $(1 \times 1 \mathrm{~mm}$ mesh $)$ on the L-layer inside the chamber, and fallen litter was removed weekly. $\mathrm{CO}_{2}$ efflux from combusted granite soil was measured 6 months from the start of the $R_{\mathrm{LL}}$ measurements. The mean $\mathrm{CO}_{2}$ flux rate $( \pm$ standard deviation $)$ was $0.00063 \pm 0.00068 \mathrm{mg} \mathrm{CO}_{2} \mathrm{~m}^{-2} \mathrm{~s}^{-1}(n=16)$ when SWC ranged from 0.05 to $0.3 \mathrm{~m}^{3} \mathrm{~m}^{-3}$ at temperatures of $24^{\circ} \mathrm{C}$. Thus, we assumed that $\mathrm{CO}_{2}$ efflux from the combusted granite soil was negligible throughout the measurement period.

For continuous in situ measurement of LWC, we used capacitance sensors as described by Ataka et al. [22]. The measurements were performed on the top surface of the L-layer and at the boundary between the L-layer and mineral soil (Fig. 1B), to capture the large vertical distribution of WC within the L-layer. We estimated average LWC from the output voltage (V) of the two sensors using the conversion equation $\mathrm{LWC}=12.73 \mathrm{~V}-3.42$ presented by Ataka et al. [22]. LWC at the forest floor shows spatial variability associated with tree canopy conditions. Thus, to reflect the LWC of the L-layer by direct measurement, two capacitance sensors were placed on the L-layer inside the chamber. To check the validity of continuous LWC monitoring, we compared the sensor values with $\mathrm{LWC}$ measured 
(A)
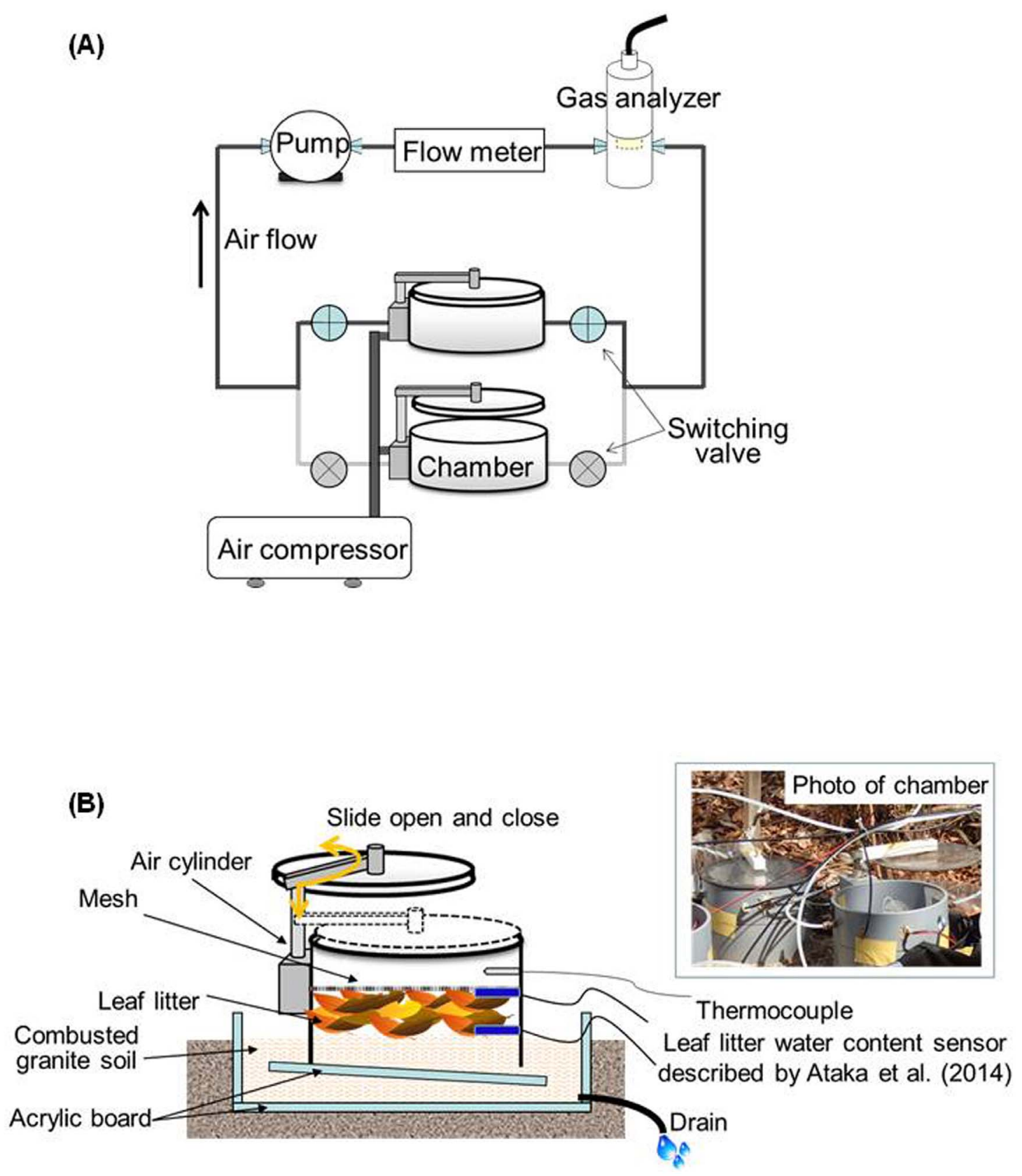

Figure 1. Schematic of the automated chamber system and the experimental design for measurement of $\mathrm{CO}_{2}$ efflux from the leaf litter layer. A. Schematic of the automated dynamic-closed chamber system for measuring leaf litter respiration and soil respiration. B. The experimental design for continuous measurement of $\mathrm{CO}_{2}$ efflux from the leaf litter layer only using automated chamber system. doi:10.1371/journal.pone.0108404.g001
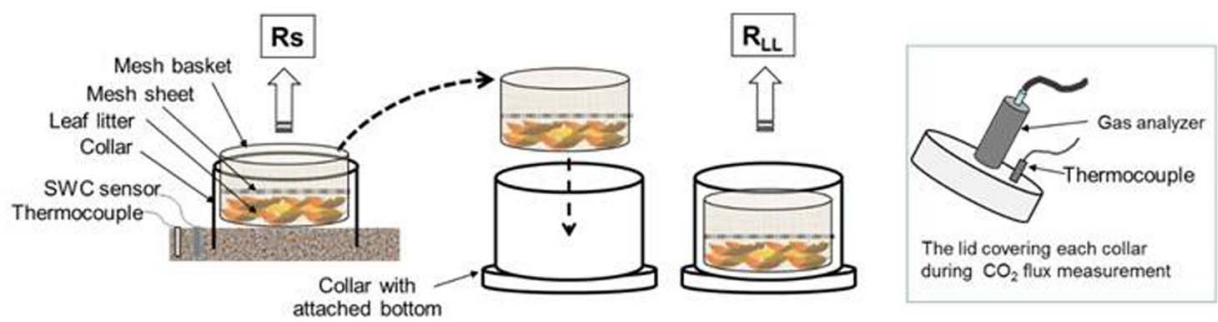

Figure 2. Schematic of the manual chamber system and the experimental design for measurement of $\mathrm{CO}_{2}$ efflux from the leaf litter layer $\left(R_{\mathrm{LL}}\right)$ and soil $\left(R_{\mathrm{S}}\right)$.

doi:10.1371/journal.pone.0108404.g002 


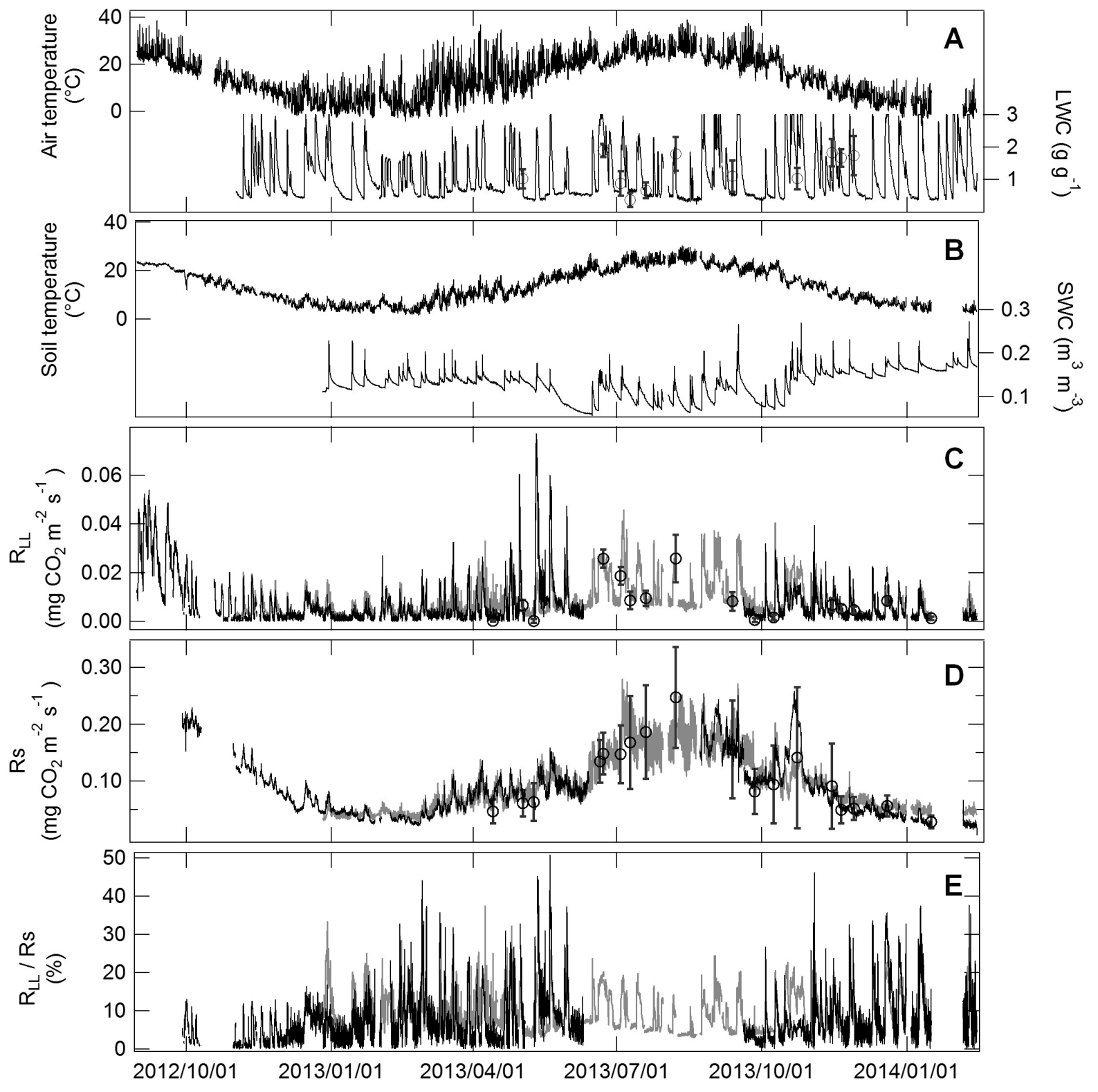

Figure 3. Seasonal variation in environmental factors, $\mathrm{CO}_{2}$ efflux from the leaf litter layer $\left(R_{\mathrm{LL}}\right)$, and soil respiration $\left(R_{\mathrm{S}}\right)$. Data were measured every $30 \mathrm{~min}$ between September 2012 and January 2014. A. Bold and fine lines show air temperature and water content of the leaf litter layer (LWC), respectively. B. Bold and fine lines show soil temperature and soil water content (SWC), respectively. C. Black and grey lines show observed and estimated $R_{\mathrm{LL}}$, respectively. D. Black and grey lines show observed and estimated $R_{\mathrm{S}}$, respectively. E. Black and grey lines show the ratio of observed and estimated $R_{\mathrm{LL}}$ to $R_{\mathrm{S}}$, respectively. Circles and bars show mean values and standard deviation of manual measurements. Estimated $R_{\mathrm{LL}}$ and $R_{S}$ were calculated from regression equations using temperature (T) and water content (WC): $R_{\mathrm{LL}}=0.29 \mathrm{e}^{0.059 \mathrm{~T}}[\mathrm{WC} /(95.04+\mathrm{WC})]$ and $R_{\mathrm{S}}=0.031 \mathrm{e}^{0.10 \mathrm{~T}}[\mathrm{WC} /(0.032+\mathrm{WC})]$. doi:10.1371/journal.pone.0108404.g003

Table 1. $Q_{10}$ of leaf litter respiration $\left(R_{\mathrm{LL}}\right)$ and soil respiration $\left(R_{\mathrm{S}}\right)$ for different water contents of the leaf litter layer (LWC) and soil (SWC).

\begin{tabular}{|c|c|c|c|c|c|c|}
\hline & \multicolumn{3}{|l|}{$R_{\mathrm{LL}}$} & \multicolumn{3}{|l|}{$R_{\mathrm{s}}$} \\
\hline & LWC $\leq 1$ & $1<$ LWC $\leq 2$ & $2<$ LWC & $S W C \leq 0.1$ & $0.1<S W C \leq 0.15$ & $0.15<S W C$ \\
\hline $\mathbf{Q}_{10}$ & 1.54 & 1.88 & 2.07 & 1.97 & 2.12 & 2.73 \\
\hline a & 0.0019 & 0.0044 & 0.0064 & 0.027 & 0.032 & 0.025 \\
\hline b & 0.043 & 0.063 & 0.073 & 0.068 & 0.075 & 0.10 \\
\hline
\end{tabular}

doi:10.1371/journal.pone.0108404.t001 

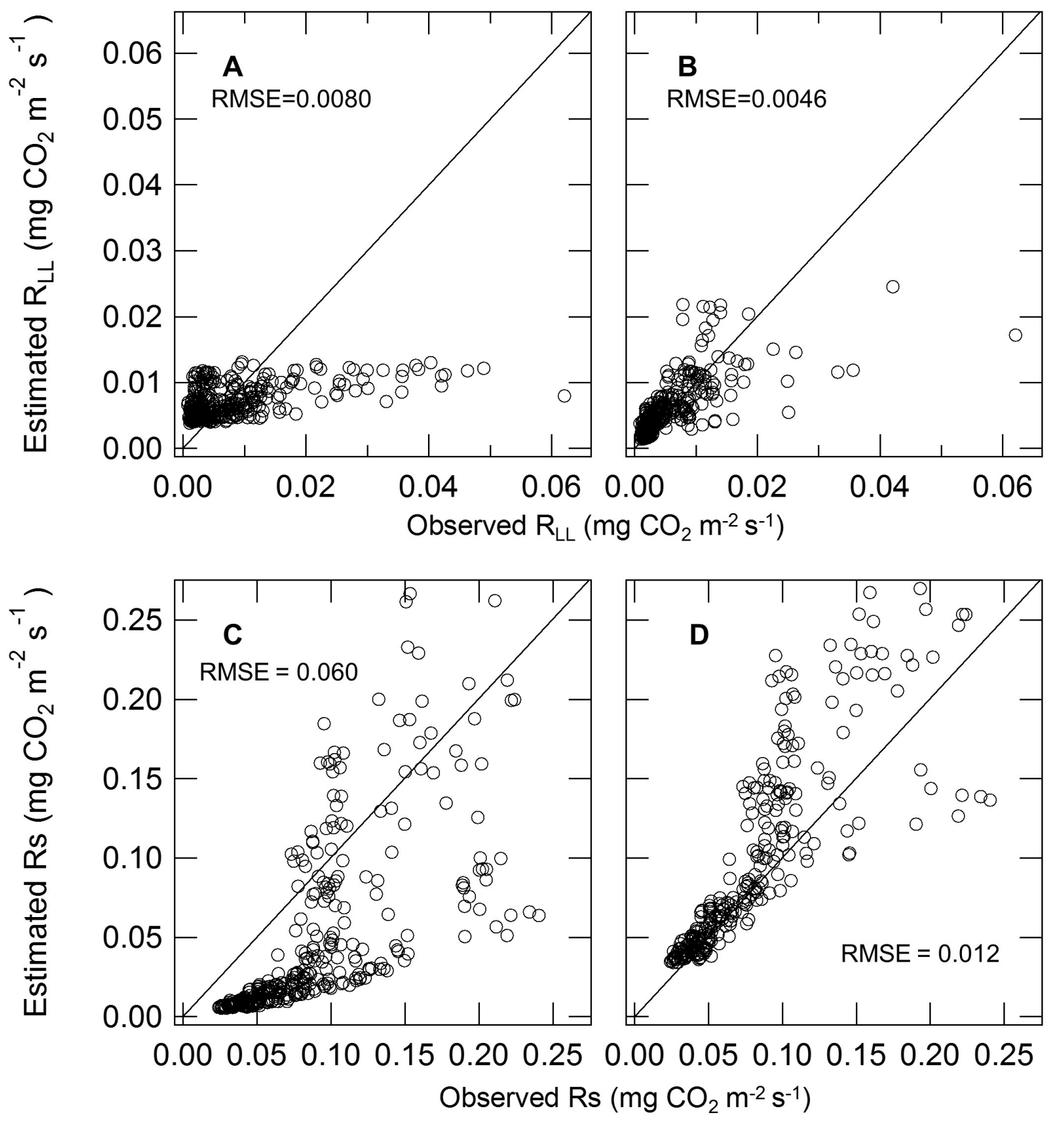

Figure 4. Relationship between observed and estimated $\mathrm{CO}_{2}$ efflux rate from leaf litter respiration $\left(R_{\mathrm{LL}}\right)$ and soil respiration $\left(R_{\mathrm{S}}\right)$. $R_{\mathrm{LL}}$ $(A, B)$ and $R s(C, D)$ show daily mean values. Estimated respiration rates were calculated using a function of temperature $(A, C)$ from Eq. $(5,6)$ and a function of temperature and water content $(B, D)$ from Eq. $(7,8)$ in the Results. Lines represent the 1:1 ratio. RMSE: root mean square error. doi:10.1371/journal.pone.0108404.g004

manually as described in the following section. In parallel with LWG measurement, soil temperature (copper-constantan thermocouple) and soil volumetric water content $\left(\mathrm{ECH}_{2} \mathrm{O}\right.$ EC-5 sensors; Decagon Devices, Pullman, WA, USA) were measured at $5-\mathrm{cm}$ depth near each chamber. The output voltage of all environmental data was recorded every 1 min with a data logger (Datamark LS$3000 \mathrm{PtV}$; Hakusan, Japan) and average values were computed every $30 \mathrm{~min}$. The environmental data, $R_{\mathrm{LL}}$, and $R_{\mathrm{S}}$ were measured continuously between September 2012 and January 2014. Malfunction of IRGA resulted in a lack of data for $R_{\mathrm{LL}}$ and $R_{\mathrm{S}}$ for $31 \%$ of the measurements.
Manual chamber method for measuring leaf litter respiration and soil respiration

To determine the validity of $R_{\mathrm{LL}}$ and $R_{\mathrm{S}}$ measured using the automated chamber method, respiration was measured using the manual chamber method. We assumed that manual chamber method allow to measure under conditions that were closer to natural than the automated chamber method. We measured $R_{\mathrm{LL}}$ and $R_{\mathrm{S}}$ manually using a static chamber system at midday on 18 days between April 2013 and January 2014. Twelve PVC collars $\left(320 \mathrm{~cm}^{2}\right.$ surface area) were placed in a $2 \times 4 \mathrm{~m}$ area in January 2013. The edges of the collars were inserted approximately $1.5 \mathrm{~cm}$ into the soil. To measure $R_{\mathrm{LL}}$, mesh baskets $(1 \times 1 \mathrm{~mm}$ mesh, the 

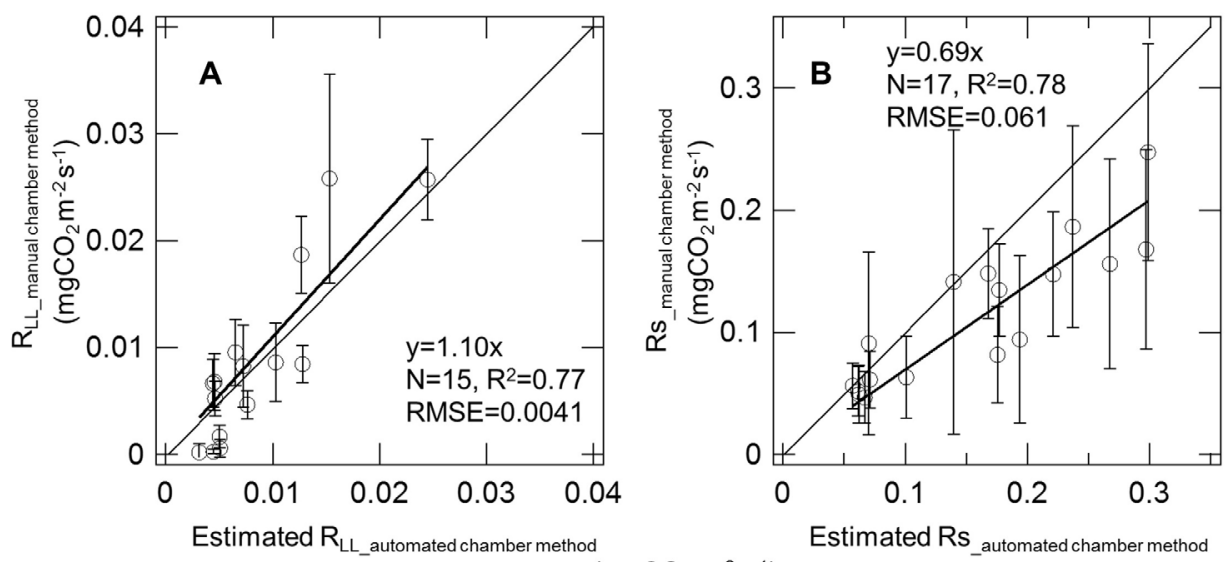

$\left(\mathrm{mgCO}_{2} \mathrm{~m}^{-2} \mathrm{~s}^{-1}\right)$

Figure 5. Relationship between respirations measured using a manual chamber method and estimated from automated chamber data. Respiration rate measured with the manual chamber method $(R$ manual chamber method) show mean value obtained from measurement of 12

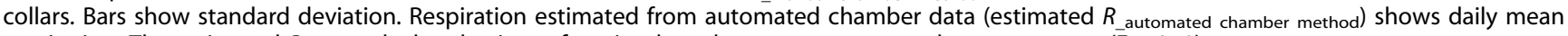
respiration. The estimated $R$ was calculated using a function based on temperature and water content (Eq. 8, 9).

doi:10.1371/journal.pone.0108404.g005

same diameter as the PVC collars; $20 \mathrm{~cm}$ ) were set into each collar and $15 \mathrm{~g}$ (dry weight) of newly fallen leaf litter was placed on the L-layer inside each basket (Fig. 2). To prevent supply of newly fallen litter, we placed a mesh sheet $(1 \times 1 \mathrm{~mm}$ mesh) on the L-layer inside the chamber, and fallen litter was removed weekly.

For measurement of $R_{\mathrm{S}}$, the collars were completely covered with lids to which an IRGA and copper-constantan thermocouple were attached. Soil temperature and SWG $(5 \mathrm{~cm}$ depth) were measured close to the collars when $R_{\mathrm{S}}$ was measured. After completing the measurements of $R_{\mathrm{S}}$, the mesh baskets were carefully removed from the collars and placed in PVC chambers (20 cm diameter, $7 \mathrm{~cm}$ high; Fig. 2). We measured $R_{\mathrm{LL}}$ using the same methods as used for $R_{\mathrm{S}}$ measurement. The temperature and $\mathrm{CO}_{2}$ concentrations in the chamber were recorded at 1-s intervals using a data logger (GL220). Linearity of the $\mathrm{CO}_{2}$ flux was checked on the data logger monitor at each measurement. The measurement period for each chamber was $10 \mathrm{~min}$ and $\mathrm{CO}_{2}$ data for the middle 5-min intervals were used to determine $R_{\mathrm{LL}}$ according to Eq. (1), excluding data from the first $3 \mathrm{~min}$.

For measurement of LWG in the mesh baskets, four or five leaves were removed from each basket and immediately placed in sealed plastic bags. Fresh weight of the leaf litter was measured in the laboratory within $24 \mathrm{~h}$ of sampling. Leaf litter samples were oven dried at $65^{\circ} \mathrm{C}$ for $48 \mathrm{~h}$, and water content $\left(\mathrm{WC} ; \mathrm{g} \mathrm{g}^{-1}\right.$ ) was calculated using Eq. 2 as follows:

$$
W C=\frac{(F W-D W)}{D W},
$$

where $F W$ is the fresh mass of the sample (g), and $D W$ is the dry mass of the sample $(\mathrm{g})$. Samples were returned to each mesh basket within 1 week after sampling.

\section{Leaf litter respiration and soil respiration rates as a function of environmental factors}

Respiration models are fundamentally described by nonlinear functions. We used the following function to investigate the response of respiration to temperature:

$$
R=a \exp (b T)
$$

where $T$ is temperature (leaf litter temperature for $R_{\mathrm{LL}}$ measurement or soil temperature for $R_{\mathrm{S}}$ measurement) and $a$ and $b$ are constants. Leaf litter temperature was assumed to be same as air temprature. $b$ is related to the $Q_{10}$ parameter $\left(Q_{10}=e^{10 b}\right)$. To determine the effects of temperature and water content on $R_{\mathrm{LL}}$ and $R_{\mathrm{S}}$, we used a function that was previously applied to estimate soil respiration by Subke and Schlesinger [26]:

$$
R=a \exp (b T)\left(\frac{W C}{c+W C}\right)
$$

where $a, b$, and $c$ are constants. LWG or SWC was used as WC in this equation. These nonlinear regressions were performed using a modified Levenberg-Marquardt method with Igor Pro 6.0 software (WaveMetrics, Lake Oswego, OR, USA). The estimated respiration values presented in this manuscript were calculated using Eq. 4.

\section{Short-term changes in $R_{\mathrm{LL}}$ and LWC on wetting and drying cycle}

To evaluate short-term changes in $R_{\mathrm{LL}}$ and $\mathrm{LWC}$ after rainfall events, we chose eight typical periods that included one wetting and drying cycle and had consecutive no rainfall days for at least 3 days. We used daily mean $R_{\mathrm{LL}}$ and LWC before the day on which precipitation occurred as the pre-wetting condition, and these values after precipitation as the post-wetting condition. Daily mean $R_{\mathrm{LL}}$ was calculated from $R_{\mathrm{LL}}$ values observed using the automated chamber method.

Effect of wetting and drying cycle of the L-layer on $R_{\mathrm{LL}}$ and $R$ s on the annual time scale

To investigate the effects of wetting and drying of the L-layer on $R_{\mathrm{LL}}$ on the annual time scale, we separated the estimated daily mean $R_{\mathrm{LL}}$ in 2013 into 'Dry' and 'Wet' periods based on daily mean $\mathrm{LWC}$ as a threshold value. The threshold $\mathrm{LWC}$ value that separated 'Dry' and 'Wet' periods for $R_{\mathrm{LL}}$ was estimated by the abovementioned short-term analyses. Daily mean $R_{\mathrm{LL}}$ was calculated from the estimated $R_{\mathrm{LL}}$ values because there were gaps in the continuous $R_{\mathrm{LL}}$ data observed using the automated 


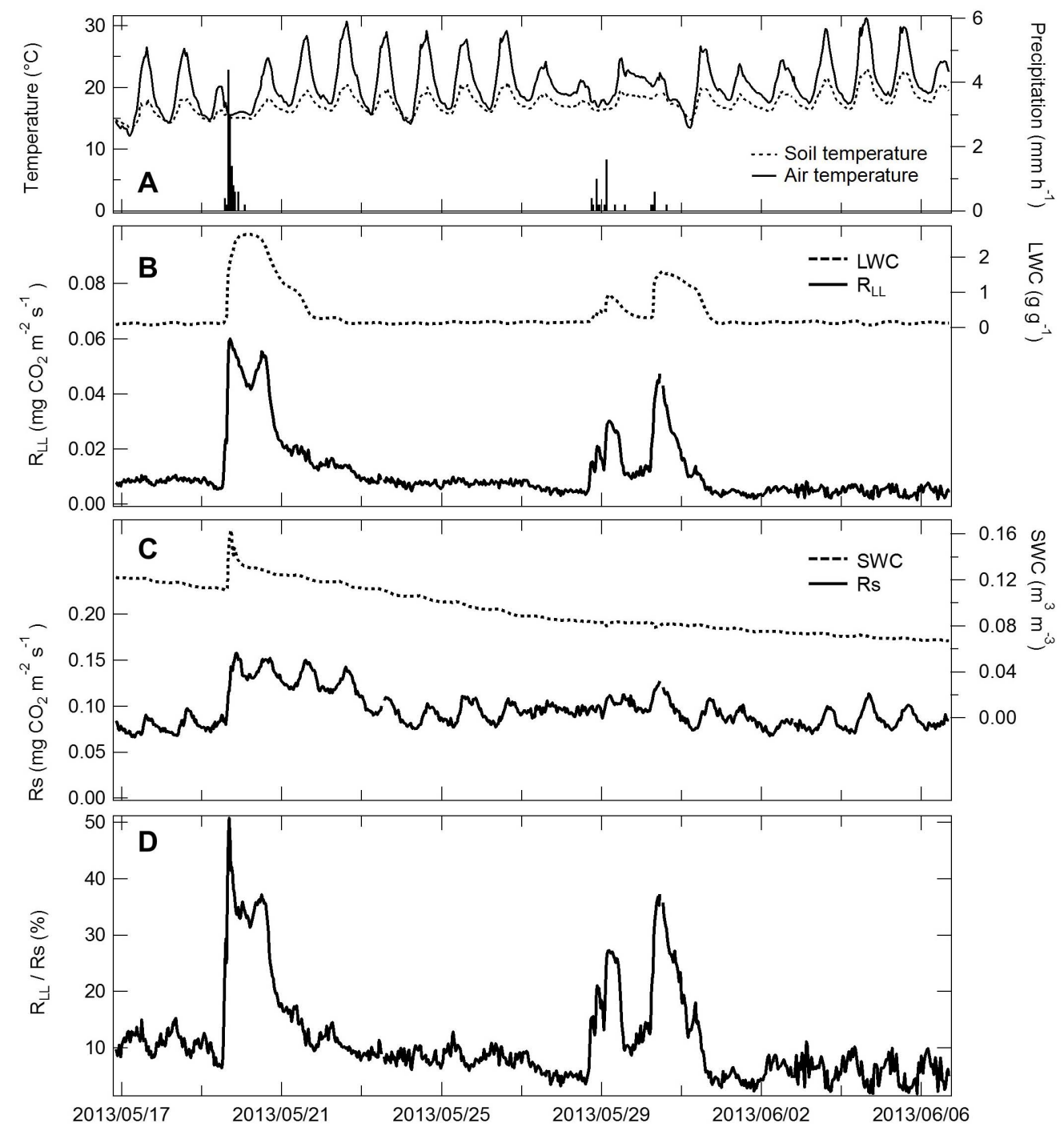

Figure 6. Temporal variation in environmental factors, $\mathrm{CO}_{2}$ efflux from the leaf litter layer $\left(R_{\mathrm{LL}}\right)$, soil respiration $\left(R_{\mathrm{S}}\right)$, and the ratio of $R_{\mathrm{LL}}$ to $R_{\mathbf{S}}$. Data was measured at one collar every $30 \mathrm{~min}$ between May 17 and June 6, 2013. A. Soil and air temperature. Spikes on the x-axis indicate precipitation events $\left(\mathrm{mm} \mathrm{h}^{-1}\right)$. B. $R_{\mathrm{LL}}$ and water content of the leaf litter layer (LWC). C. $R_{\mathrm{S}}$ and soil water content (SWC). D. The ratio of $R_{\mathrm{LL}}$ to $R_{\mathrm{S}}(\%)$. doi:10.1371/journal.pone.0108404.g006

chambers. We estimated the contribution of $R_{\mathrm{LL}}$ accumulated during the wet and dry period to total $R_{\mathrm{S}}$.

\section{Results}

Seasonal variation in $R_{\mathrm{LL}}$ and $R_{\mathrm{S}}$

The magnitude of the peak in the observed $R_{\mathrm{LL}}$ pulse was higher in summer than in winter (Fig. $3 \mathrm{C}) . R_{\mathrm{LL}}$ values were low when LWC was low (Fig. 3A, G). $R_{\mathrm{S}}$ changed substantially according to temperature (Fig. 3B, D), with higher values in summer than in winter. The relationships between respiration and temperature were described by the following functions:

$$
\begin{gathered}
R_{L L}\left(m g \mathrm{CO}_{2} m^{-2} s^{-1}\right)=0.0038 \exp \left(0.065 \times T_{L L}\right) \\
R s\left(m g \mathrm{CO}_{2} m^{-2} s^{-1}\right)=0.0031 \exp (0.19 \times T s)
\end{gathered}
$$

where $T_{\mathrm{LL}}$ is leaf litter temperature and $T_{\mathrm{s}}$ is soil temperature $\left({ }^{\circ} \mathrm{C}\right)$.
To evaluate effect of $\mathrm{WC}$ on the temperature sensitivity of respiration, the measured respiration data was separated into three groups based on WC (Table 1). More than 14\% of total respiration data was included in each WC group. $R_{\mathrm{LL}}$ showed low values when WC values were low in spite of high temperature. Consequently, calculated $Q_{10}$ values for not only $R_{\mathrm{LL}}$ but also $R_{\mathrm{S}}$ decreased with decreasing WC. The relationships between respiration and temperature and $\mathrm{WC}$ were described by the following functions:

$$
\begin{aligned}
& R_{L L}\left(m g \mathrm{CO}_{2} m^{-2} s^{-1}\right)= \\
& 0.29 \exp \left(0.059 \times T_{L L}\right)\left(\frac{L W C}{95.04+L W C}\right), \\
& R s\left(m g \mathrm{CO}_{2} m^{-2} s^{-1}\right)= \\
& 0.031 \exp (0.10 \times T s)\left(\frac{S W C}{0.032+S W C}\right),
\end{aligned}
$$




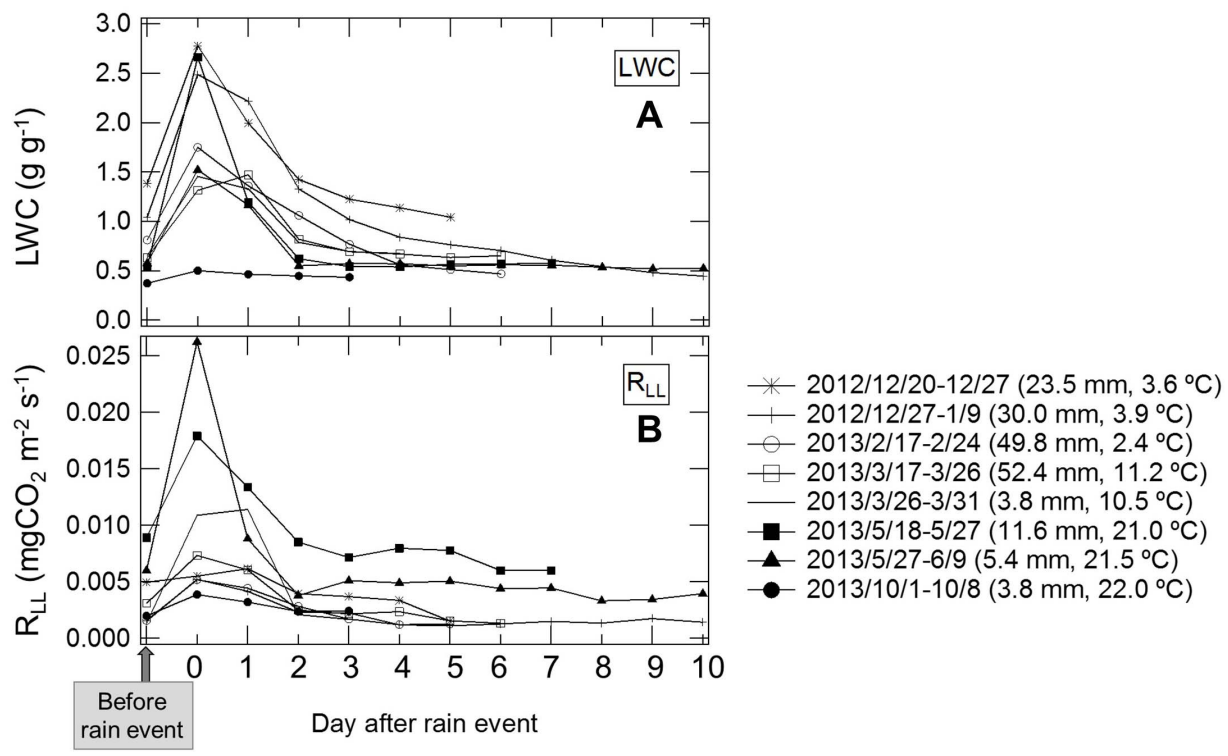

Figure 7. Temporal variation in water content of the leaf litter layer (LWC) and $\mathrm{CO}_{2}$ efflux from the leaf litter layer $\left(R_{\mathrm{LL}}\right)$ after rainfall events. LWC (A) and $R_{\mathrm{LL}}$ (B) show the daily mean values. The rainfall intensity of each precipitation event was $23.5 \mathrm{~mm}$ in 2 days (2012/12/20-12/27, mean air temperature; $\left.3.6^{\circ} \mathrm{C}\right) ; 30.0 \mathrm{~mm}$ in 3 days $\left(2012 / 12 / 27-1 / 9,3.9^{\circ} \mathrm{C}\right) ; 49.8 \mathrm{~mm}$ in 2 days $\left(2013 / 2 / 17-2 / 24,2.4^{\circ} \mathrm{C}\right) ; 52.4 \mathrm{~mm}$ in 3 days $(2013 / 3 / 17-$ $\left.3 / 26,11.2^{\circ} \mathrm{C}\right) ; 3.8 \mathrm{~mm}$ in 2 days $\left(2013 / 3 / 26-3 / 31,10.5^{\circ} \mathrm{C}\right) ; 11.6 \mathrm{~mm}$ in 2 days $\left(2013 / 5 / 18-5 / 27,21.0^{\circ} \mathrm{C}\right) ; 5.4 \mathrm{~mm}$ in 3 days $\left(2013 / 5 / 27-6 / 9,21.5^{\circ} \mathrm{C}\right) ;$ and $3.8 \mathrm{~mm}$ in 4 days $\left(2013 / 10 / 1-10 / 8,22.0^{\circ} \mathrm{C}\right)$.

doi:10.1371/journal.pone.0108404.g007

where LWC $\left(\mathrm{g} \mathrm{g}^{-1}\right)$ and SWC $\left(\mathrm{m}^{3} \mathrm{~m}^{-3}\right)$ are water content of leaf litter and soil, respectively. The RMSE between observed and estimated daily mean respiration based on temperature $\left(R_{\mathrm{LL}}\right.$, $\left.0.0080 \mathrm{mg} \quad \mathrm{CO}_{2} \mathrm{~m}^{-2} \mathrm{~s}^{-1} ; R_{\mathrm{S}}, 0.060 \mathrm{mg} \quad \mathrm{CO}_{2} \mathrm{~m}^{-2} \mathrm{~s}^{-1}\right)$ was larger than that based on temperature and WC $\left(R_{\mathrm{LL}}, 0.0046 \mathrm{mg}\right.$ $\mathrm{CO}_{2} \mathrm{~m}^{-2} \mathrm{~s}^{-1} ; R_{\mathrm{S}}, 0.012 \mathrm{mg} \mathrm{CO}_{2} \mathrm{~m}^{-2} \mathrm{~s}^{-1}$ ) (Fig. 4). Estimated respiration was calculated using the equation based on temperature and WC because of the lower RMSE. Throughout the measurement period, the contribution of observed $R_{\mathrm{LL}}$ to variation in $R_{\mathrm{S}}$ changed from nearly zero to $51 \%$ following a rainfall event (Fig. 3E).

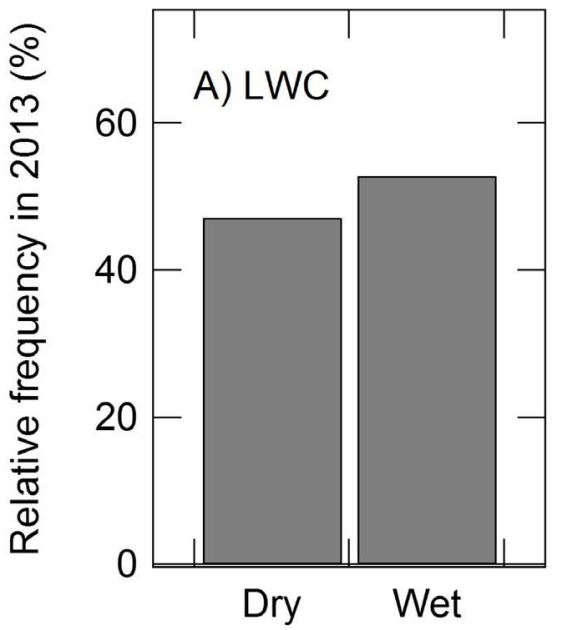

To consider the validity of $R_{\mathrm{LL}}$ and $R_{\mathrm{S}}$ estimated from continuous measurement, we compared these values with respiration rates measured using the manual chamber method (Fig. 5). Estimated respiration was very similar to that observed using manual measurements. The RMSE between estimated and observed respiration were 0.0041 and $0.061 \mathrm{mg} \mathrm{CO}_{2} \mathrm{~m}^{-2} \mathrm{~s}^{-1}$ for $R_{\mathrm{LL}}$ and $R_{\mathrm{S}}$, respectively.

Temporal changes in $R_{\mathrm{LL}}$ and $R_{\mathrm{S}}$ on the short-term scale

To show clear temporal variation in $R_{\mathrm{LL}}$ and $R_{\mathrm{S}}$, the period between May 17 and June 6, 2013 (Fig. 6) was chosen because this

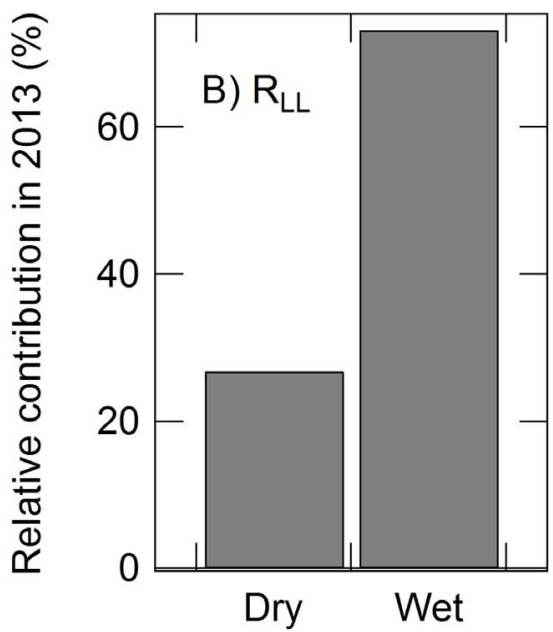

Figure 8. Histograms of the relative frequency of "Dry" and "Wet" periods in relation to water content of the leaf litter layer (LWC), and the relative contribution of estimated leaf litter respiration $\left(\boldsymbol{R}_{\mathrm{LL}}\right)$ in $\mathbf{2 0 1 3}$. The daily mean LWC (A) and $R_{\mathrm{LL}}(\mathrm{B})$ were used to present histograms. Estimated respiration rates were calculated using a function based on temperature (T) and water content $(\mathrm{WC}) . R_{\mathrm{LL}}=0.29 \mathrm{e}^{0.059 T}[\mathrm{WC} /$ (95.04+WC)]. The daily mean LWC and $R_{\mathrm{LL}}$ were defined as Dry or Wet based on LWC. Days in which daily mean LWC $<0.75 \mathrm{~g} \mathrm{~g}^{-1}$ were defined as Dry periods, while days in which daily mean LWC $\geq 0.75 \mathrm{~g} \mathrm{~g}^{-1}$ were defined as Wet periods. doi:10.1371/journal.pone.0108404.g008 
period included two characteristic rainfall events. The rainfall intensity was $11.6 \mathrm{~mm}$ over $13 \mathrm{~h}$ during the first event and $5.4 \mathrm{~mm}$ over $46 \mathrm{~h}$ during the second event. LWC and SWC increased from 0.11 to $2.64 \mathrm{~g} \mathrm{~g}^{-1}$ and from 0.11 to $0.16 \mathrm{~m}^{3} \mathrm{~m}^{-3}$, respectively, following the first rainfall event (Fig. 6B, G). LWC increased from 0.16 to $1.58 \mathrm{~g} \mathrm{~g}^{-1}$ but SWG did not increase after the second rainfall event.

Temporal variation in $R_{\mathrm{LL}}$ measured using the automated chamber system changed according to wetting and drying of the L-layer (Fig. 6B), reaching a maximum of 0.060 and $0.047 \mathrm{mg}$ $\mathrm{CO}_{2} \mathrm{~m}^{-2} \mathrm{~s}^{-1}$ during first and second rainfall events, respectively. $R_{\mathrm{S}}$ increased following the increase in SWC and subsequently decreased gradually with diurnal variation according to temperature (Fig. 6C). Between May 17 and June 6, 2013, the contribution of $R_{\mathrm{LL}}$ to $R_{\mathrm{S}}$ increased from $6.5 \%$ to $51 \%$, with a peak value of $51 \%$ during the first rainfall event and $37 \%$ during the second rainfall event (Fig. 6D).

Both $R_{\mathrm{LL}}$ and LWC reached a peak during or one day after rainfall events (Fig. 7). The peak of $R_{\mathrm{LL}}$ and LWC varied from 0.0020 to $0.026 \mathrm{mg} \mathrm{CO}_{2} \mathrm{~m}^{-2} \mathrm{~s}^{-1}$ and from 0.50 to $2.66 \mathrm{~g} \mathrm{~g}^{-1}$, respectively. Peak value of each rainfall event highly depended on air temperature. High peaks of $R_{\mathrm{LL}}$ were observed in the warm season $\left(0.017 \mathrm{mg} \quad \mathrm{CO}_{2} \mathrm{~m}^{-2} \mathrm{~s}^{-1} ; 2013 / 5 / 18-5 / 27,0.026 \mathrm{mg}\right.$ $\mathrm{CO}_{2} \mathrm{~m}^{-2} \mathrm{~s}^{-1} ; 2013 / 5 / 27-6 / 9$ in Fig. 7). Also, the peak value was related to LWC: low peak of $R_{\mathrm{LL}}$ was observed when LWC was low (0.004 mg $\mathrm{CO}_{2} \mathrm{~m}^{-2} \mathrm{~s}^{-1} ; 2013 / 10 / 1-10 / 8$ in Fig. 7). The relationship between $\mathrm{LWC}$ and amout of precipitation was not clear. In the cold season, peak values of $R_{\mathrm{LL}}$ were relatively low (e.g., $0.005 \mathrm{mg} \mathrm{CO} \mathrm{CO}^{-2} \mathrm{~s}^{-1}$; 2013/2/17-2/24, $0.006 \mathrm{mg}$ $\mathrm{CO}_{2} \mathrm{~m}^{-2} \mathrm{~s}^{-1} ; 2012 / 12 / 20-12 / 27$ in Fig. 7) even when the Llayer was wet enough (LWC more than $1.5 \mathrm{~g} \mathrm{~g}^{-1}$ ). The peak values of $R_{\mathrm{LL}}$ were 1.2 - to 8.6 -fold higher than the $R_{\mathrm{LL}}$ values before rainfall events, and $R_{\mathrm{LL}}$ fell to pre-wetting levels within 2-4 days after rainfall events and peak LWC values were 1.3- to fivefold higher than LWC before rainfall, and LWC also dropped to pre-wetting levels within 2-4 days after rainfall events. We defined $R_{\mathrm{LL}}$ from the period just after rainfall events through 2-4 days later as the " $R_{\mathrm{LL}}$ pulse".

\section{Effects of wetting and drying of the L-layer on $R_{\mathrm{LL}}$ and $R_{\mathrm{S}}$ on the annual time scale}

Estimated daily mean $R_{\mathrm{LL}}$ in 2013 was separated into 'Dry' and 'Wet' periods based on daily mean LWC. Days for which mean LWC was $<0.75 \mathrm{~g} \mathrm{~g}^{-1}$ were categorized as Dry, while days for which mean $\mathrm{LWC} \geq 0.75 \mathrm{~g} \mathrm{~g}^{-1}$ were categorized as Wet. The threshold value $\left(0.75 \mathrm{~g} \mathrm{~g}^{-1}\right)$ was obtained from mean LWG 3 days after a rainfall event (Fig. 7A). The relative frequency of Dry and Wet periods in 2013 were $47.2 \%$ and $52.8 \%$, respectively, while the relative contributions of daily mean $R_{\mathrm{LL}}$ during the Dry and Wet periods in 2013 were $26.9 \%$ and $73.2 \%$, respectively (Fig. 8). Annual $R_{\mathrm{LL}}$ and $R_{\mathrm{S}}$ in 2013 were estimated to be 0.69 and $7.94 \mathrm{t}$ C ha $\mathrm{y}^{-1}$, respectively. The RMSE between continuous respiration measured and estimated based on temperature and WC was 0.011 and $0.029 \mathrm{t} \mathrm{Cha}^{-1} \mathrm{y}^{-1}$, respectively.

The contribution of annual $R_{\mathrm{LL}}$ to $R_{\mathrm{S}}$ was $8.6 \%$. The relative frequency of LWC was similar during Dry and Wet periods, while the contribution of $R_{\mathrm{LL}}$ during the Wet period was approximately three-fold higher than that during the Dry period (Fig. 8).

\section{Discussion}

As seen in Fig. 6, $R_{\mathrm{LL}}$ immediately increased with wetting of the L-layer and decreased to pre-wetting levels within 2-4 days after rainfall events, which was consistent with observations made in previous studies $[17,19] . R_{\mathrm{LL}}$ showed no diurnal variation despite a diurnal temperate range $>10^{\circ} \mathrm{C}$. Consequently, the $Q_{10}$ of $R_{\mathrm{LL}}$ increased with increasing LWC (Table. 1). The variation in $\mathrm{Q}_{10}$ would be directly related to water stress experienced by microorganism. This indicated that $\mathrm{LWC}$ can reach to adequate low value, suspected as water stress for microorganism, within several days after rainfall. On the one hand, $R_{\mathrm{S}}$ increased during rainfall and subsequently decreased, showing diurnal variation. The $Q_{10}$ of $R_{\mathrm{S}}$ also increased with increasing SWC. Dannoura et al. [27] reported that root respiration showed little change with variation in SWG compared with changes in $R_{\mathrm{S}}$. Therefore, the increased $Q_{10}$ of $R_{\mathrm{S}}$ with increasing SWC might be highly affected by not only $R_{\mathrm{LL}}$ but also by respiration from other heterotrophic sources.

Although the relative frequency of LWC was similar during Dry and Wet periods, the contribution of annual $R_{\mathrm{LL}}$ during the Wet period was approximately three-fold higher than that during the Dry period (Fig. 8), indicating strong effect of rainfall on $R_{\mathrm{LL}}$. Although the $R_{\text {LL }}$ pulse can last for only 3-4 days after a rainfall event, this pulse would determine a large part of annual $R_{\mathrm{LL}}$. This suggests that the magnitude of total $R_{\mathrm{LL}}$ may be influenced by the frequency of rainfall events, especially in summertime, rather than the intensity of rainfall. Still, the cumulative $R_{\mathrm{LL}}$ in the Dry period contributed $26.9 \%$ of annual $R_{\mathrm{LL}}$ in 2013 , even though instantaneous $R_{\mathrm{LL}}$ was very low. There may be large vertical variability in WC and $R_{\mathrm{LL}}$ within the L-layer, indicating that higher WC and $R_{\mathrm{LL}}$ occur in lower parts of the L-layer during the drying process because the upper L-layer dries more rapidly [28]. In that case, although the mean WC of the L-layer was very low, local wetting in lower sections would produce small $\mathrm{CO}_{2}$ fluxes. Despite low instantaneous $R_{\mathrm{LL}}$, the accumulation of $R_{\mathrm{LL}}$ over a long time period (approximately $6 \mathrm{mo}$ ) resulted in a substantial contribution (27\%) of Dry-period respiration to annual $R_{\mathrm{S}}$.

Raindrops first reach the L-layer and then percolate to the soil layers below. Small amounts of precipitation caused no change in SWC or $R_{\mathrm{S}}$, but $R_{\mathrm{LL}}$ increased rapidly with increasing LWC (Fig. 6). In semi-arid and arid ecosystems, wetting of the L-layer and surface soil by small fog-drop pulses during the dry season can contribute up to $35 \%$ of $R_{\mathrm{S}}$ [29]. Although such small water inputs (e.g., brief rain showers and fog), which mainly affect the surface of the forest floor, can be significant drivers of temporal variation in $R_{\mathrm{S}}$, the soil water content sensors (generally inserted at depths $>$ $5 \mathrm{~cm}$ ) could not capture these inputs. Continuous measurement of LWC allowed for realistic modeling of the effects of rapid changes in $\mathrm{LWC}$ on $R_{\mathrm{LL}}$.

Although the annual contribution of $R_{\mathrm{LL}}$ to $R_{\mathrm{S}}$ was relatively small $(8.6 \%)$, this contribution showed large temporal variation according to rainfall, ranging from nearly zero to $51 \%$. Several other studies have described similar results $[17,21]$. For example, Borken et al. [17] reported that peaks in $R_{\mathrm{LL}}$ during addition of water ranged from 0.031 to $0.071 \mathrm{mg} \mathrm{CO}_{2} \mathrm{~m}^{-2} \mathrm{~s}^{-1}$ in vitro, which represented $11-26 \%$ of maximum in situ $R_{\mathrm{S}}$ in the Harvard forest, although $R_{\mathrm{LL}}$ before addition of water was nearly zero. These findings indicate that $R_{\mathrm{LL}}$ is a significant component of rapid and transient temporal variation in $R_{\mathrm{S}}$ in relation to rainfall events. Although numerous studies have examined $\mathrm{CO}_{2}$ efflux from mineral soils in relation to the intensity, duration, and frequency of rainfall [30,31], few studies have focused on $R_{\mathrm{LL}}$ because of the difficulty in measuring this dynamic. Here, $R_{\mathrm{LL}}$ pulses were observed only during and several days after rainfall events. Thus, periodic sampling (e.g., twice per week) might be insufficient to capture the contribution of the $R_{\mathrm{LL}}$ pulse to $R_{\mathrm{S}}$. Moreover, manual flux measurements are usually not performed during precipitation events because of difficulties that can occur 
with electronic instruments and sampling methods. In our view, conducting in situ measurements of $\mathrm{CO}_{2}$ efflux from the L-layer only over short time intervals (e.g., up to $1 \mathrm{~h}$ ) produces robust data for understanding the response of $R_{\mathrm{LL}}$ to rainfall events and its contribution to $R_{\mathrm{S}}$.

The contribution of $R_{\mathrm{LL}}$ to annual $R_{\mathrm{S}}$ was $8.6 \%$ in our site. In an oak forest, the contribution of $R_{\mathrm{LL}}$ to $R_{\mathrm{S}}$ was $23 \%$, according to model simulation based on temperature and LWC by Hanson et al. [13]. Ngao et al. [32] reported a lower contribution (8\%) in a beech forest, estimated using an isotope mass balance approach, which was close to the value observed at our site $(8.6 \%)$. However, simple quantitative comparisons between studies are difficult because of the use of different methods. In addition, some technical problems remain at our site. First, we performed $R_{\mathrm{LL}}$ measurements in the treatment area in which the mineral soil below the L-layer was replaced with combusted granite soil. This treatment may have affected the microbial community and environmental conditions in the L-layer. Secondly, each continuous measurement of $R_{\mathrm{LL}}$ and $R_{\mathrm{S}}$ was performed with single chambers, so spatial heterogeneity in $R_{\mathrm{LL}}$ and $R_{\mathrm{S}}$ were not considered. Automated chamber methods allowed high-interval measurements of temporal variation in respiration but had poorer spatial distribution compared with the manual chamber method. The balance of trade-offs between automated and manual chamber method is subject to the relative importance of characterizing temporal and spatial variability of individual $\mathrm{CO}_{2}$ sources. The number of chambers used can enhance the accuracy of measured mean values. Loescher et al. [33] reported that the number of chambers needs to be $>100$ to adequately represent spatial variability. However, this is not a feasible experimental design because of practical limitations to sampling efforts. To improve estimation of $R_{\mathrm{LL}}$ and $R_{\mathrm{S}}$ at the forest stand level, and to better understand the soil carbon budget, a comprehensive comparison of the diverse $\mathrm{G}$ pools and fluxes in forest soils is required.

\section{Conclusions}

In our study, the rapid and transient variation in $R_{\mathrm{LL}}$ induced by rainfall; the peak $R_{\mathrm{LL}}$ was observed during or one day after rainfall, and $R_{\mathrm{LL}}$ subsequently decreased to pre-wetting levels

\section{References}

1. Curtis PS, Hanson PJ, Bolstad P, Barford C, Randolph JC, et al. (2002) Biometric and eddy-covariance based estimates of annual carbon storage in five eastern North American deciduous forests. Agricultural and Forest Meteorology 113: 3-19.

2. Kominami Y, Jomura M, Dannoura M, Goto Y, Tamai K, et al. (2008) Biometric and eddy-covariance-based estimates of carbon balance for a warmtemperate mixed forest in Japan. Agricultural and Forest Meteorology 148: 723737

3. Keith H, Leuning R, Jacobsen KL, Cleugh HA, van Gorsel E, et al. (2009) Multiple measurements constrain estimates of net carbon exchange by a Eucalyptus forest. Agricultural and Forest Meteorology 149: 535-558.

4. Yuste JC, Nagy M, Janssens IA, Carrara A, Ceulemans R (2005) Soil respiration in a mixed temperate forest and its contribution to total ecosystem respiration. Tree Physiology 25: 609-619.

5. Hanson PJ, Edwards NT, Garten CT, Anderson JA (2000) Separating root and soil microbial contributions to soil respiration: A review of methods and observations. Biogeochemistry 48: 115-146.

6. Kuzyakov Y (2006) Sources of $\mathrm{CO}_{2}$ efflux from soil and review of partitioning methods. Soil Biology \& Biochemistry 38: 425-448.

7. Moyano FE, Kutsch WL, Rebmann C (2006) Soil respiration fluxes in relation to photosynthetic activity in broad-leaf and needle-leaf forest stands. Agricultural and Forest Meteorology 148: 135-143.

8. Suseela V, Conant RT, Wallenstein MD, Dukes JS (2012) Effects of soil moisture on the temperature sensitivity of heterotrophic respiration vary seasonally in an old-field climate change experiment. Global Change Biology 18: 336-348. within 2-4 days after rainfall events, following the decrease in LWC. On the one hand, $\mathrm{CO}_{2}$ efflux from coarse woody debris found in our site decreased during rainfall events, and subsequently, a gradual increase in $\mathrm{CO}_{2}$ efflux continued for at least 14 days until next rainfall [34]. Therefore, coarse woody debris was a $\mathrm{CO}_{2}$ efflux source over longer time scales, while $R_{\mathrm{LL}}$ approached nearly zero within a few days after rainfall events, even at high temperatures. Such specific temporal $\mathrm{CO}_{2}$ efflux patterns for each heterotrophic source when subjected to wetting and drying cycles would be a result of substrate properties (e.g., specific surface area). In our view, continuous and direct measurements of $\mathrm{CO}_{2}$ efflux and environmental conditions characterized by substrate properties of individual $\mathrm{CO}_{2}$ sources could improve understanding of the processes that regulate variation in heterotrophic respiration and $R_{\mathrm{S}}$ and enable progress beyond empirical models that are primarily based on simple temperature and SWC relationships.

Moreover, the magnitude of heterotrophic respiration under wetting and drying cycles is strongly related to microbial physiology and community composition. For example, Schnurer et al. [35] showed that longer-duration wetting could promote microbial biomass, causing an increase in basal respiration. Fierer et al. [36] showed the influence of drying and rewetting frequency on microbial (fungi and bacteria) community composition. To improve understanding of heterotrophic respiration associated with response and adaptation of microorganisms under climatic changes, collected continuous in situ data for $\mathrm{CO}_{2}$ efflux and environmental conditions (e.g., temperature and $\mathrm{WC}$ ) of individual $\mathrm{CO}_{2}$ sources should be combined with analyses of microbial physiology and community composition.

\section{Acknowledgments}

We greatly thank Dr. Yoshiko Kosugi and the staff of the Forest Hydrology Laboratory of Kyoto University for assistance in the field and for helpful advice.

\section{Author Contributions}

Conceived and designed the experiments: MA YK TM. Performed the experiments: MA KY MT. Analyzed the data: MA YK MT. Contributed reagents/materials/analysis tools: MA MJ. Contributed to the writing of the manuscript: MA.

9. Jomura M, Kominami Y, Tamai K, Miyama T, Goto Y, et al. (2007) The carbon budget of coarse woody debris in a temperate broad-leaved secondary forest in Japan. Tellus B 59: 211-222.

10. Matsumoto A, Kominami Y, Ishii H (2010) Field measurement of heterotrophic respiration of root litter using a small chamber system. Journal of Forest Research 92(5): 269-272.

11. Tewary CK, Pandey U, Singh JS (1982) Soil and litter respiration rates in different microhabitats of a mixed oak-conifer forest and their control by edaphic conditions and substrate quality. Plant and Soil 65: 233-238.

12. Kirschbaum MUF (2013) Seasonal variations in the availability of labile substrate confound the temperature dependence of organic matter decomposition. Soil Biology \& Biochemistry 57: 568-576.

13. Hanson PJ, O'Neill EG, Chambers MLS, Riggs JS, Joslin JD, et al. (2003) Soil respiration and litter decomposition. In: North America Temperate Deciduous Forest Responses to Changing Precipitation Regimes (eds Hanson PJ and Wullschleger SD). Springer, New York.

14. Andersson M, Kjoller A, Struwe S (2004) Microbial enzyme activities in leaf litter, humus and mineral soil layers of European forests. Soil Biology \& Biochemistry 36: 1527-1537.

15. DeForest JL, Chen J, McNulty SG (2009) Leaf litter is an important mediator of soil respiration in an oak-dominated forest. International Journal of Biometeorology 53(2): 1432-1254.

16. Wilson TB, Kochendorfer J, Meyers TP, Heuer M, Sloop K, et al. (2014) Soil respiration in a mixed temperate forest and its contribution to total ecosystem respiration. Agricultural and Forest Meteorology 192-193: 42-50. 
17. Borken W, Davidsona EA, Savagea K, Gaudinskib J, Trumborec SE (2003) Drying and wetting effects on carbon dioxide release from organic horizons. Soil Science Society of American Journal 67: 1888-1896.

18. Orchard VA, Cook FJ (1983) Relationship between soil respiration and soil moisture. Soil Biology \& Biochemistry 15(4): 447-453.

19. Lee X, Wu HJ, Sigler J, Oishi C, Siccama T (2004) Rapid and transient response of soil respiration to rain. Global Change Biology 10: 1017-1026.

20. Goulden ML, Miller SD, da Rocha HR, Menton MC, de Freitas HC, et al. (2004) Diel and seasonal patterns of tropical forest $\mathrm{CO}_{2}$ exchange. Ecological Application 14: 42-54.

21. Cisneros Dozal LM, Trumbore S, Hanson PJ (2007) Effect of moisture on leaf litter decomposition and its contribution to soil respiration in a temperate forest. Journal of Geophysical Research 112: 148-227.

22. Ataka M, Kominami, Miyama T, Yoshimura K, Jomura M, et al. (2014) Using capacitance sensors for the continuous measurement of the water content in the litter layer of forest soil. Applied and Environmental Soil Science 2014:

23. Tamai K, Hattori S (1994) Modeling of evaporation from forest floor in a deciduous broad-leaved forest and its application to basin. Journal of the Japanese Forestry Society 76: 233-241 (in Japanese with English summary).

24. Kaneko S, Akieda N, Naito F, Tamai K, Hirano Y (2007) Nitrogen budget of a rehabilitated forest on a degraded granitic hill. Journal of Forest Research 12: 38-44.

25. Goto Y, kominami Y, Miyama T, Tamai K, Kanazawa Y (2003) Aboveground biomass and net primary production of a broad-leaved secondary forest in the southern part of Kyoto prefecture, central Japan. Bulletin of FFPRI 387: 115147 (in Japanese with English summary).

26. Subke JA, Reichstein M, Tenhunen JD (2003) Explaining temporal variation in soil $\mathrm{CO}_{2}$ efflux in a mature spruce forest in Southern Germany. Soil Biology \& Biochemistry 35: 1467-1483.
27. Dannoura M, Kominami Y, Tamai K, Jomura M, Miyama T, et al. (2006) Development of an automatic chamber system for long-term measurements of $\mathrm{CO}_{2}$ flux from roots. Tellus 58B: 502-512.

28. Ataka M, Kominami Y, Jomura M, Yoshimura K, Uematsu C (2014) $\mathrm{CO}_{2}$ efflux from leaf litter focused on spatial and temporal heterogeneity of moisture. Journal of Forest Research 19: 295-300.

29. Carbone MS, Still CJ, Ambrose AR, Dawson TE, Williams AP, et al. (2011) Seasonal and episodic moisture controls on plant and microbial contributions to soil respiration. Oecologia 167: 265-278.

30. Borken W, Matzner E (2009) Reappraisal of drying and wetting effects on C and N mineralization and fluxes in soils. Global Change Biology 15: 808-824.

31. Birch HF (1958) The effect of soil drying on humus decomposition and nitrogen availability. Plant and Soil 10: 9-31.

32. Ngao J (2005) Estimating the contribution of leaf litter decomposition to soil $\mathrm{CO}_{2}$ efflux in a beech forest using 13C-depleted litter. Global Change Biology 11(10): 1768-1776.

33. Loescher HW, Law BE, Mahrt L, Hollinger DY, Campbell J, et al. (2006) Uncertainties in, and interpretation of, carbon flux estimates using the eddy covariance technique. Journal of Geophysical Research 111: D21S90.

34. Jomura M, Kominami Y, Kanazawa Y (2005) Long-term measurements of the $\mathrm{CO}_{2}$ flux from coarse woody debris using an automated chamber system. Journal of the Japanese Forest Society 87(2): 138-144 (in Japanese with English summary).

35. Schnurer J, Clarholm M, Bostrom S, Rosswall T (1986) Effects of moisture on soil microorganisms and nematodes: A field experiment. Microbial Ecology 12(2): $217-230$.

36. Fierer N, Schimel JP, Holden PA. (2003) Influence of drying-rewetting frequency on soil bacterial community structure. Microbial Ecology 45(1): 6371. 